\section{Uma universidade e dois modelos: a representação linear e em malha para o campus da Universidade Estadual de Maringá Renan Augusto Avanci, Fabíola Castelo de S. Cordovil}

Renan Augusto Avanci é Mestre em Arquitetura e urbanismo; Universidade Estadual de Maringá; renanavanci@hotmail.com

Fabíola Castelo de S. Cordovil é Doutora em Arquitetura e urbanismo; Professora do Programa de Pós-graduação em Arquitetura e Urbanismo - PPU/UEM; fabiolacordovil@gmail.com

\section{Resumo}

Os dois planos propostos pelos arquitetos Jaime Lerner, Domingos Bongestabs e Marcos Prado para o campus da Universidade Estadual de Maringá (UEM) na década de 1970 são tomados como objetos de reflexão e como expressão de possíveis representações organizacionais do espaço universitário. Em síntese, tratamos da representação linear configurada pelo projeto inicial da Universidade em 1970 e da representação em malha concebida por meio de um novo plano proposto para o campus em 1977. Entendendo a necessidade de revisitar essas propostas que permearam o ideário de configuração espacial da universidade em questão, propomos a apresentação destes planos e de suas consequentes representações formais. Deste modo, pretendemos contribuir à compreensão de possíveis meios de organização das universidades, atentando aos aspectos de implantação e articulação dos edifícios inseridos no campus universitário. Entendemos, por fim, que o território que se planejou para a UEM e suas consequentes representações e atributos, consideram estratégias espaciais que estimulam a construção de uma unidade espacial, a integração das atividades e a flexibilização dos espaços de ensino. Todavia, a transição entre as propostas, a primeira funcional e plástica e a segunda em malha não ortogonal, resultou em um espaço marcado pela complexidade e ilegibilidade.

Palavras-chave: universidade linear, universidade em malha, campus universitário.

\footnotetext{
Abstract

The two plans proposed by the architects Jaime Lerner, Domingos Bongestabs and Marcos Prado to the campus of the State University of Maringá (UEM) in the 1970s are taken as objects of reflection and as an expression of possible organizational representations of university space. In short, we treat the linear representation set by the initial project of the University in 1970 and the reticulate representation proposed to new plan for the campus in 1977. Understanding the need to revisit the proposals that permeated the spatial ideas configuration of university concerned, we propose the presentation of these plans and their consequent formals representations. That way, we intend to contribute to the understanding of possible means of organization of universities, paying attention to implementation aspects and articulation of buildings entered the university campus. Finally, we understanding that the territory that was planned for UEM and its subsequent representations and attributes, consider spatial strategies that stimulate the construction of a unit space, the integration of activities and the flexibility of teaching spaces. However, the transition between the proposals, the first functional and plastic and the second in not orthogonal grid, resulting in a space marked by complexity and illegibility.
}

AVANCI, Renan Augusto; CORDOVIL, Fabíola Castelo de S. Uma universidade e dois modelos: a representação linear e em malha para o campus da Universidade Estadual de Maringá. Thésis, Rio de Janeiro, v. 2, n. 4, p. 24-44, nov./ dez. 2017

data de submissão: 11/01/2017 data de aceite: $22 / 11 / 2017$ 
Keywords: linear university, reticulate university, campus.

\section{Resumen}

Los dos planes propuestos por los arquitectos Jaime Lerner, Domingos Bongestabs y Marcos Prado en el campus de la Universidad Estatal de Maringá (UEM) en la década de 1970 se toman como objeto de reflexión y como expresión de posibles representaciones de organización del espacio universitario. En definitiva, tratamos a la representación lineal establecido por el proyecto inicial de la Universidad en 1970 y la representación en malla diseñada por un nuevo plan propuesto para el campus en 1977. La comprensión de la necesidad de volver a examinar las propuestas que impregnaron la configuración espacial de las ideas de la universidad, se propone la presentación de estos planes y sus consiguientes manifestaciones formales. Por lo tanto, tenemos la intención de contribuir a la comprensión de las posibles formas de organización de las universidades, prestando atención a los aspectos de implementación y articulación de los edificios entró en el campus universitario. Creemos, por último, que el territorio que estaba previsto para la UEM y sus posteriores representaciones y atributos, tenga en cuenta las estrategias espaciales que estimulan la construcción de una unidad de espacio, la integración de las actividades y la flexibilidad de los espacios docentes. Sin embargo, la transición entre las propuestas, la primera plástica y funcional y la segunda en la cuadrícula no ortogonal, resultou en un espacio marcado por la complejidad y la ilegibilidad.

Palabras clave: universidad lineales, universidad de malla, campus.

\section{Planos e contexto}

Q uando o arquiteto Klaus Alberto escreveu sobre megaestruturas em seu artigo "Interfaces brutalistas: megaestruturas universitárias" de 2013,

1 Os estudos de Reyner Banham (1976) sobre os grandiosos e complexos projetos que se tornaram correntes na década de 1960 apontaram o desenvolvimento de uma nova proposta tipológica no contexto da arquitetura e do urbanismo. Essa tipologia, popularizada por "megaestruturas" foi abordada em seu livro "Megaestructuras, futuro urbano del passado reciente" cuja primeira edição datou-se no ano de 1976. Banham discorre nesta obra literária sobre os mais variados aspectos envolvendo a formalização e aplicação dessa solução projetual. O estudo percorre a ação dos pioneiros e iniciantes da tipologia passando pelos equipamentos arquitetônicos e propostas urbanas as quais foram aplicadas, entre elas as universidades. também empregadas na conformação dos espaços acadêmicos nas décadas de 1960 e 1970, considerando, duas representações megaestruturais: os edifícios lineares e os edifícios em malha. Do mesmo modo, Christine Mahler em sua tese de doutoramento defendida em 2015 e intitulada "Territórios universitários: tempos, espaços e formas" retratou algumas possibilidades de configuração do espaço acadêmico, entre elas, os sistemas retilíneos e em trama.

Ambos os autores constroem seus discursos em análises de universidades implantadas mundialmente nas décadas de 1960 e 1970, período de institucionalização da Universidade Estadual de Maringá (UEM). Internacionalmente, debruçaram-se sobre exemplos de instituições lineares como as universidades inglesas de Essex projetada por Keneph Capon e a de East Anglia, projetada pelo arquiteto Denys Lasdun. No contexto canadense apresentaram os edifícios alongados do Scarborough College da Universidade de Toronto idealizado por John Andrews e a Universidade de 
Lethbridge de Arthur Erickson. No mesmo caminho, trataram da Universidade de Calábria projetada por Vittorio Gregotti e Dänen Martensson em Cosenza na Italia e do edifício universitário linear de Craig Ellwood para o Art Center College of Design na Califórnia USA. No ambiente nacional, o estudo sobre os edifícios universitários lineares recaiu sobre a Universidade de Brasília (UnB) a partir da estrutura alongada de Oscar Niemeyer para o Instituto de Ciências (ICC).

Perante as representações em malha, as pesquisas de Alberto (2013) e Mahler (2015) voltaram-se especificamente para a concepção da Universidade Livre de Berlin ${ }^{2}$ projetada por George Candilis juntamente com os parceiros arquitetos Alexis Josics e Shadrach Woods. No âmbito do Brasil, os estudos apontaram o Centro Universitário da Pampulha da Universidade Federal de Minas Gerais (UFMG) e as intervenções modulares no campus da Universidade de São Paulo (USP).

Não foram poucas as vezes que essas universidades foram identificadas e propagadas no período de suas instalações como exemplos de instituições que respondiam às necessidades de uma renovação do ensino superior e de sua consequente estrutura física. Para Alberto (2013, p.17), são universidades que configuraram como tributos a "racionalização das soluções técnicas, modulação, flexibilidade, aumento da longevidade funcional do edifício e pré-fabricação". Do mesmo modo para Mahler (2015, p.254), "tais definições se adequam ao perfil de um projeto de universidade no qual foram consideradas questões de porte, flexibilidade, crescimento, economia e longa duração".

Os estudos de Banham (1976) sobre os grandiosos e complexos projetos que se tornaram correntes na década de 1960 e 1970 apontaram o desenvolvimento de uma nova proposta tipológica no contexto da arquitetura e do urbanismo. Essa tipologia, popularizada por "megaestruturas", foi abordada em seu livro "Megaestructuras, futuro urbano del passado reciente", publicado em 1976, no qual o autor discorre sobre os mais variados aspectos envolvendo a formalização, a aplicação e a decadência dessa solução projetual em propostas de equipamentos urbanos, entre eles as universidades.

Banham (1976) afirmou que todas megaestruturas são grandes edifícios, mas nem todos grandes edifícios se consolidaram como megaestruturas existindo uma definição específica para o termo. Para conceituá-lo o autor referenciou considerações de outros estudiosos do assunto. Um deles é Fumihiko Maki que, em sua obra "Investigations in Collective Form" (1964), defi-
2 Apontamos também a Universidade em sistema de malha de Toulouse-de-Mirail projetada pelos mesmos arquitetos na França. 
niu a megaestrutura como um grande edifício envolvendo todas as funções de uma cidade ou parte dela. Outra consideração é a de Ralph Wilcoxon (1968) que definiu a megaestrutura não apenas como um edifício de grandes dimensões, mas, também, como uma estrutura que frequentemente está construída em unidades modulares.

Por certo, este pensamento construtivo em desenvolver uma tipologia fundamentada na adição e sistematização de componentes modulares foi determinado pelo ideário de uma "arquitetura tecnológica" que via na pré-fabricação a solução mais adequada para compor um sistema que investisse em novas tecnologias e que acompanhasse a expansão do fordismo e a formação dos mercados de massa diante das novas circunstâncias sociais e econômicas emergentes a partir do pós-guerra. No contexto dos anos 1960 esta postura arquitetônica destacou-se por meio das publicações e dos experimentos projetuais do grupo Archigram (CABRAL, 2002; 2004).

Como princípios, o grupo Archigram confiou na ideia de um progresso ilimitado por meio do crescimento industrial e do surgimento dos novos materiais e das novas disponibilidades tecnológicas que permitiria superar todas as condicionantes da arquitetura tradicional. Para além disso, confiavam na existência de uma racionalização intrínseca no mundo da tecnologia e da ciência capaz de solucionar todos os problemas do tempo e fornecer uma melhora dos aspectos sociais. Como resposta, os arquitetos do movimento conceberam diversas propostas radicais "desde pequenas células intercambiáveis até gigantes cidades no espaço que a agregação destas cápsulas poderiam gerar" (MONTANER, 2001, p. 113).

Para Cabral (2002) o grupo, de fato, acumulou uma série de projetos experimentais e de cunho especulativo que visavam uma renovação da herança moderna por meio dos recursos tecnológicos e das formas da cultura de massa. Segundo a autora, uma maneira otimista em aproximar o homem das novas tecnologias.

De fato, o surgimento dessas novas tendências arquitetônicas deu-se principalmente pelo contínuo avanço tecnológico que se manifestou ao longo da arquitetura do século $X X$ e prosperou nos anos sessenta nos países mais industrializados. De modo geral, foram movimentos que buscavam novas formas arquitetônicas a partir das novas possibilidades tecnológicas por intermédio do avanço da produção construtiva, do surgimento de novos materiais e das possibilidades de 
cálculo e projeção das estruturas arquitetônicas que, a partir de então, puderam ser construídas em série (MONTANER, 2001). A arquitetura como expressão tecnológica foi de certo modo propagada como um arranjo sistêmico que buscou por meio das grandes estruturas pré-fabricadas, moduladas e flexíveis uma maneira de ordenar o espaço caotizado, entre outras circunstâncias, pelo pós-guerra.

Em meio a esta contextualização, os projetos propostos para o campus da Universidade Estadual de Maringá (UEM) na década de 1970 aproximam-se das representações espaciais que trataram de ordenar o território universitário a partir de organizações sistêmicas.

A primeira espacialização proposta para a UEM deuse pelo projeto inicial da Universidade em 1970. Este projeto configurou-se a partir da implantação de dois grandiosos pares de blocos configurados linearmente e agrupados por meio de uma ampla praça central. A segunda proposta deu-se em 1977 quando a Universidade propôs a idealização de um novo plano para o campus. A concepção desta nova proposta apresentou uma configuração sistêmica concebida por múltiplos pavilhões inseridos sob uma malha triangular equalizadora dos espaços.

Ainda que o primeiro plano não tenha se materializado, sendo o segundo, a matriz para o desenvolvimento da Universidade, ambos os planos trazem a macroestruturação dos meios de organização do território universitário a partir de representações e morfologias largamente adotadas nos programas universitários daquele período. Portanto, a relevância da espacialidade linear do plano de 1970 e da configuração em malha do plano de 1977 torna-se mais evidente à medida que essas representações espaciais traduzem diferentes formas arquitetônicas e urbanísticas de composição dos espaços acadêmicos.

Portanto, apresentamos a análise do plano de 1970 destacando o conceito de sua representação linear, o contexto na qual se estabelece, bem como suas aproximações em relação a outros campi que se construíam no período a partir de megaestruturas lineares. Abordamos os motivos que levaram à solicitação pela Universidade para a elaboração de uma nova proposta após sete anos da primeira. Tais premissas, de ordem econômica e de composição espacial, sugeriram maior flexibilidade e a possibilidade de verticalização que resultou numa configuração reticulada aliada à racionalidade e à rapidez na construção. Por fim, consideramos os efeitos e os resultados da significativa alteração sobre a proposta inicial. 


\section{A representação linear: o plano de 1970}

Do ponto de vista conceitual, os arquitetos responsáveis pelo primeiro plano da UEM definiram que a Universidade seria um lugar de encontro e de intercâmbio de ideias entre professores, estudantes e pesquisadores. Neste sentido, a concepção do espaço universitário como uma grande comunidade configurou-se como o princípio elementar na proposta arquitetônica do campus. A ideia fundamental permeava a criação de uma instituição integrada entre quatro entidades principais: os institutos, as faculdades, a administração e os órgãos complementares como o museu, a biblioteca, o setor de esportes e o centro de conferências. Como parte do programa, estes quatro conjuntos de edificações estariam organizados no campus de forma a conceber uma vida comum entre todos os usuários (MARINGÁ, 1971).

Para o atendimento desta conceituação, o primeiro plano configurou a Universidade a partir da organização e concentração das atividades acadêmicas em grandes edifícios, separando a circulação de pedestres da circulação de veículos e distanciando os setores de recreação, de saúde e de habitação das edificações didáticas.

O setor didático apresentou-se em dois conjuntos de blocos retilíneos no sentido de maior dimensão do terreno. O maior bloco concentrou a parte de ensino e o menor, acomodou os serviços gerais. Entre os mesmos, implantou-se um Centro de Conferências circundado por um espaço livre. Definiu-se por meio deste local o principal acesso à Universidade e à implantação de alguns setores de interesses comuns aos usuários como, a Reitoria, a Biblioteca, o Museu e o Restaurante fixados às margens destes edifícios. O espaço entre os dois pavilhões foi nomeado de "Grande Praça" e sua delimitação dar-se-ia pelo formato linear dos edifícios didáticos que, ao encontro da praça, deixavam de ser retilíneos apresentando linhas curvas nas quatro alas que se abriam ao espaço central.

Esta postura de implantação revelou que certamente o setor didático compôs um princípio de integração que o define como o partido fundamental da concepção espacial do plano proposto. Assim como na proposta do ICC de Niemeyer para a UnB, "todos os campos do conhecimento estariam unidos sob um mesmo teto, sem grandes distinções" (ALBERTO, 2008, p.263). Neste sentido, a concepção da edificação didática em monobloco abrigaria os diversos departamentos dentro de uma estrutura única. 


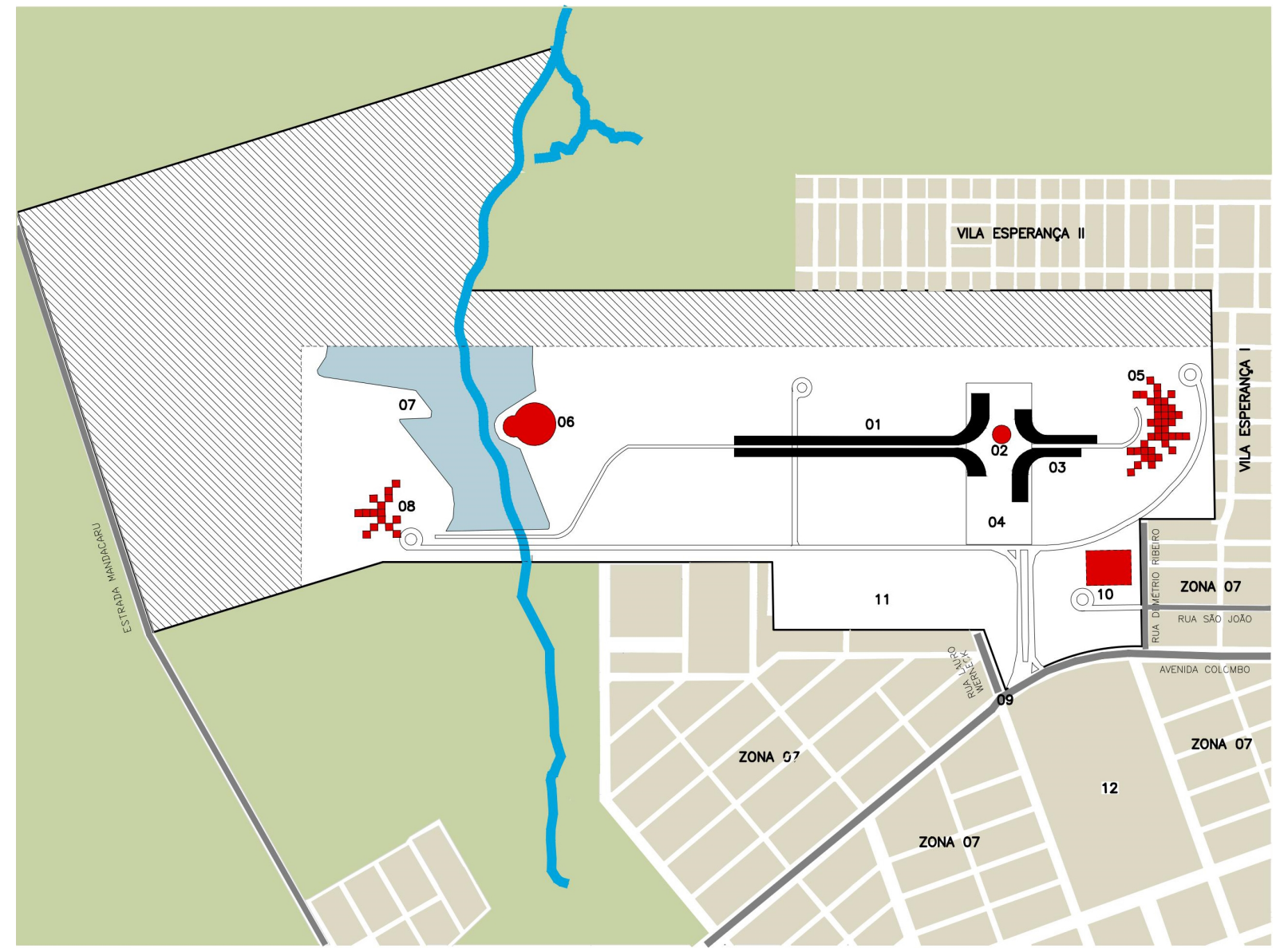

Figura 1

Implantação Geral Plano UMA.Fonte: Mapa Base - Pranchas 01 e 02 do Plano de Implantação Imediata - $1^{\circ}$ Sub-Etapa Plano UMA

Fonte: Arquivo digital disponível no COMCAP-UEM. Desenho: Renan Avanci. Legenda:

01 - Ensino/pesquisa - Biblioteca - Comunicações - Computação, 02 - Centro de Conferências, 03 - Reitoria / Serviços gerais, 04 - Grande Praça, 05 - Centro de Vivência (Habitação Estudantil), 06 - Teatro ao ar livre, 07 - Lago, 08 - Clube do Lago, 09 - Passagem subterrânea (trincheira), 10 - Hospital Escola, 11 - Estacionamento.

Desde os primeiros debates universitários desenvolvidos no Brasil, a partir da década de 1930, o conceito de proximidade física, incentivando e fortalecendo a integração humana no espaço de ensino superior, foi fundamental para construir o conceito de cidades universitárias. De uma implantação isolada de escolas na malha urbana, como é o caso das primeiras faculdades do país, passando pela ideia de uma concentração em um espaço específico para o saber com a criação de cidades universitárias, chega-se com o projeto de Niemeyer, à sobreposição de usos e funções, cada vez mais aproximando os usuários. Essa proposta foi representada com a criação de um edifício único para, virtualmente, "tudo" e "todos" (ALBERTO, 2008, p.264).

$O$ resultado da concepção linear proposta pela equipe Lerner para o pavilhão didático estabeleceu uma edificação de dois pavimentos e um subsolo com aproximadamente quinhentos e quarenta metros de comprimento e trinta e seis metros de largura. Toda a extensão do edifício rigidamente composta por módulos de dezoito metros. 
O interior do bloco de ensino organizou-se em duas alas separadas por um corredor central de quatorze metros de largura. Ambas as alas com espacialidades compatíveis de doze metros de largura e comprimento variável de acordo com a modulação prevista para cada ambiente e sua respectiva função. Neste sentido, o plano estabeleceu dois tamanhos para as salas de aula. O maior formato de cento e vinte metros quadrados para o atendimento de oitenta e quatro alunos e o menor de sessenta metros quadrados atendendo quarenta e dois universitários. Quanto às unidades administrativas, os departamentos e as instalações sanitárias seguiram um tamanho padrão.

No sentido longitudinal o bloco didático foi dividido em três partes. Estas representando as três etapas previstas para a construção do edifício. Segundo o plano, a edificação linear se concretizaria totalmente de acordo com as necessidades físicas e demanda estudantil da Universidade. Em específico, a primeira e terceira etapas estruturaram as salas de aula, as unidades administrativas, os laboratórios e as instalações sanitárias. Já a segunda, implantou no subsolo uma passagem viária para o acesso de veículos ao bloco didático. Ao mesmo tempo, também deu continuidade à implantação das salas de aulas, dos laboratórios e dos departamentos. O acesso principal ao interior do bloco de ensino deu-se pelo pavimento térreo. Embora este pavimento estivesse a dois metros e quarenta abaixo do nível do setor cívico, foi neste piso que se apresentou a conexão do edifício linear com a Grande Praça.

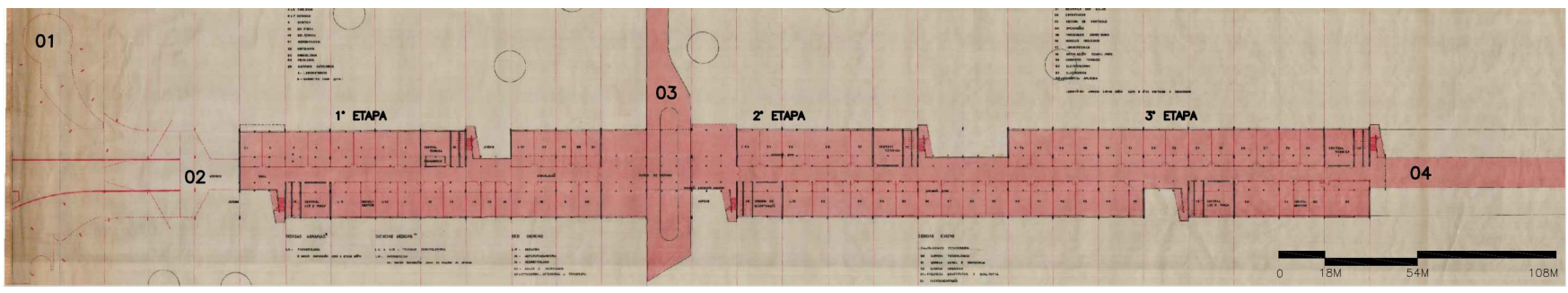

Figura 2

Subsolo Bloco Didático - Plano UMA. Fonte: Prancha 08 do Plano de Implantação Imediata - $1^{\circ}$ Sub-Etapa Plano UMA.

Fonte: Arquivo digital disponível no COMCAP-UEM.

Legenda:

01 - Biblioteca, 02 - Acesso Pedestre, 03 - Acesso Veículos, 04 - Circulação externa pedestre.

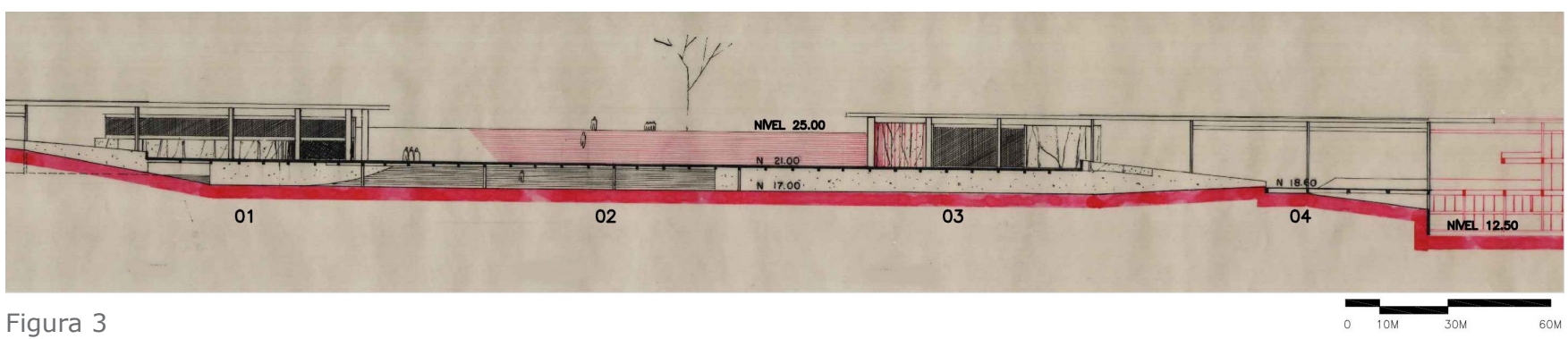

Figura 3

Corte - Acesso bloco didático Plano UMA. Fonte: Prancha 10 do Plano de Implantação Imediata $-1^{\circ}$

Sub-Etapa Plano UMA

Fonte: Arquivo digital disponível no COMCAP-UEM.

Legenda: 01 - Biblioteca, 02 - Acesso Pedestre, 03 - Acesso Veículos, 04 - Circulação externa pedestre. 
A separação do ensino e da pesquisa dentro da edificação didática deu-se pela disposição dos laboratórios e salas de aula nos três pavimentos planejados. No subsolo, instalaram-se predominantemente os laboratórios científicos com pé-direito de cinco metros. Já no pavimento térreo, cuja altura da edificação diminuiu para três metros e setenta, a disposição dos espaços voltou-se ao atendimento das unidades administrativas, departamentos e algumas salas de ensino. No último pavimento, as duas alas laterais abrigaram somente as salas de aula. No corredor central deste piso um grande vazio de seis metros de largura e sessenta metros de comprimento permitiria luminosidade ao pavimento térreo, uma vez que parte da cobertura geral do edifício linear configurava uma claraboia central.

Ao adentrar o pavimento térreo do bloco didático acessado pela Grande Praça, projetou-se um pátio coberto conforme especificação das plantas e cortes apresentados no anteprojeto. Na verdade, este espaço conformar-se-ia como um prolongamento do grande hall de acesso ao edifício. A partir desse espaço, o universitário acederia o principal corredor de circulação configurado no pavimento intermediário. Deste piso, os demais pavimentos da edificação seriam acessados por meio de escadas locadas em pontos específicos. Basicamente, locou-se um sistema de circulação vertical nas extremidades de cada etapa construtiva proposta para a edificação.

A mobilidade do transeunte no interior do edifício didático definiu-se pelo amplo corredor central distribuído pelos três pavimentos da edificação. A concepção deste corredor foi claramente ilustrada em uma perspectiva apresentada pelo projeto. A imagem demonstra que os arquitetos idealizaram este caminho ao mesmo tempo como um local de passagem e como um ponto de encontro.

São evidentes as aproximações formais do bloco linear da equipe Lerner com a postura de organização das megaestruturas lineares e especialmente com o ICC de Niemeyer.

De modo geral, os projetos de universidades em edifícios únicos separam claramente as salas de aula dos laboratórios e as ocupações destas funções dentro do bloco didático desenvolvem-se em níveis permitindo uma divisão por pavimento do ensino e da pesquisa. No edifício linear do Plano UMA, as salas de aula ocuparam o pavimento térreo e o pavimento superior, sendo o subsolo tomado pelos laboratórios. 


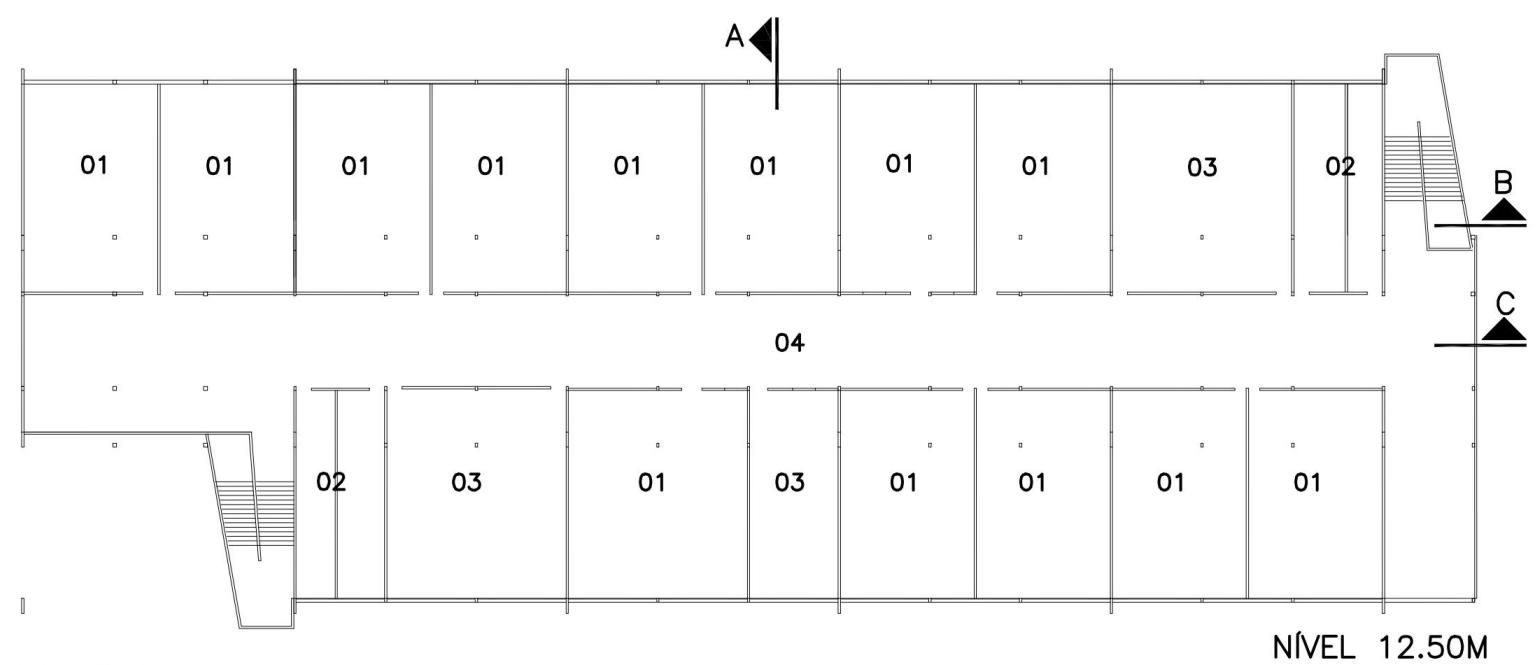

SUBSOLO

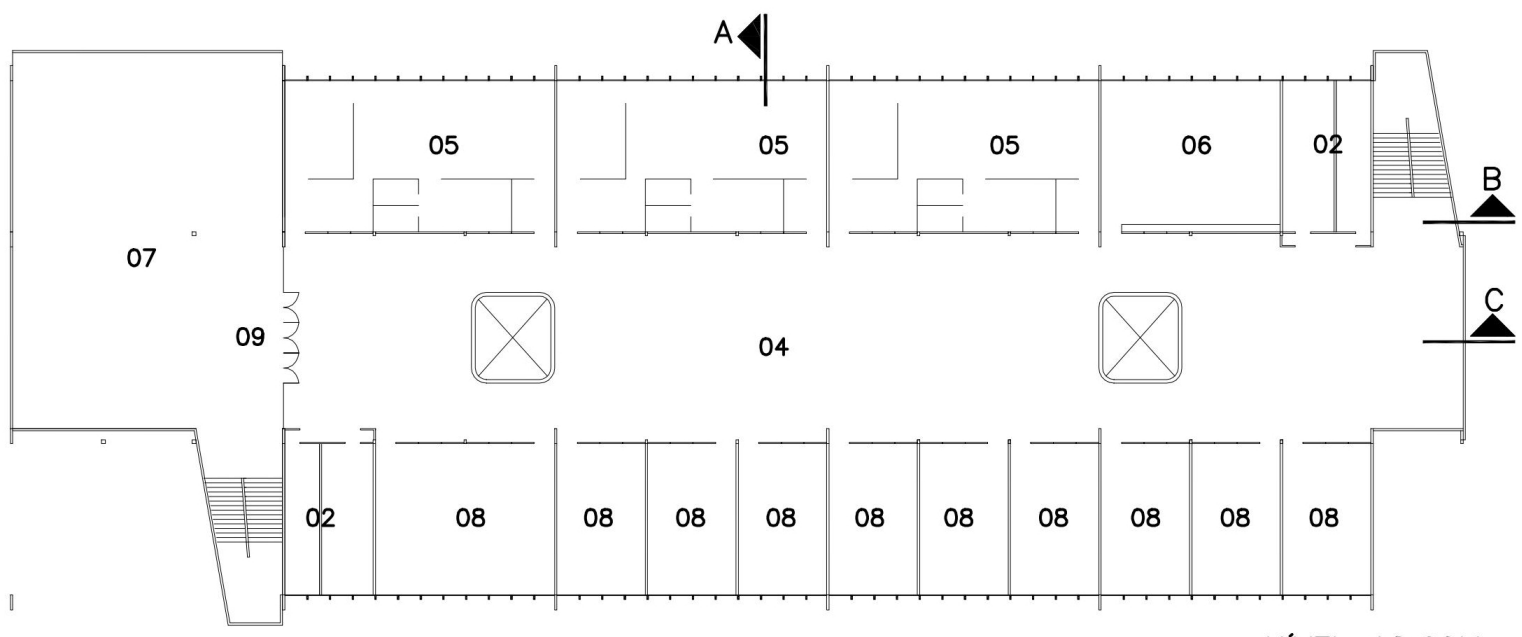

PAVIMENTO TERREO

NIVEL $18.60 \mathrm{M}$

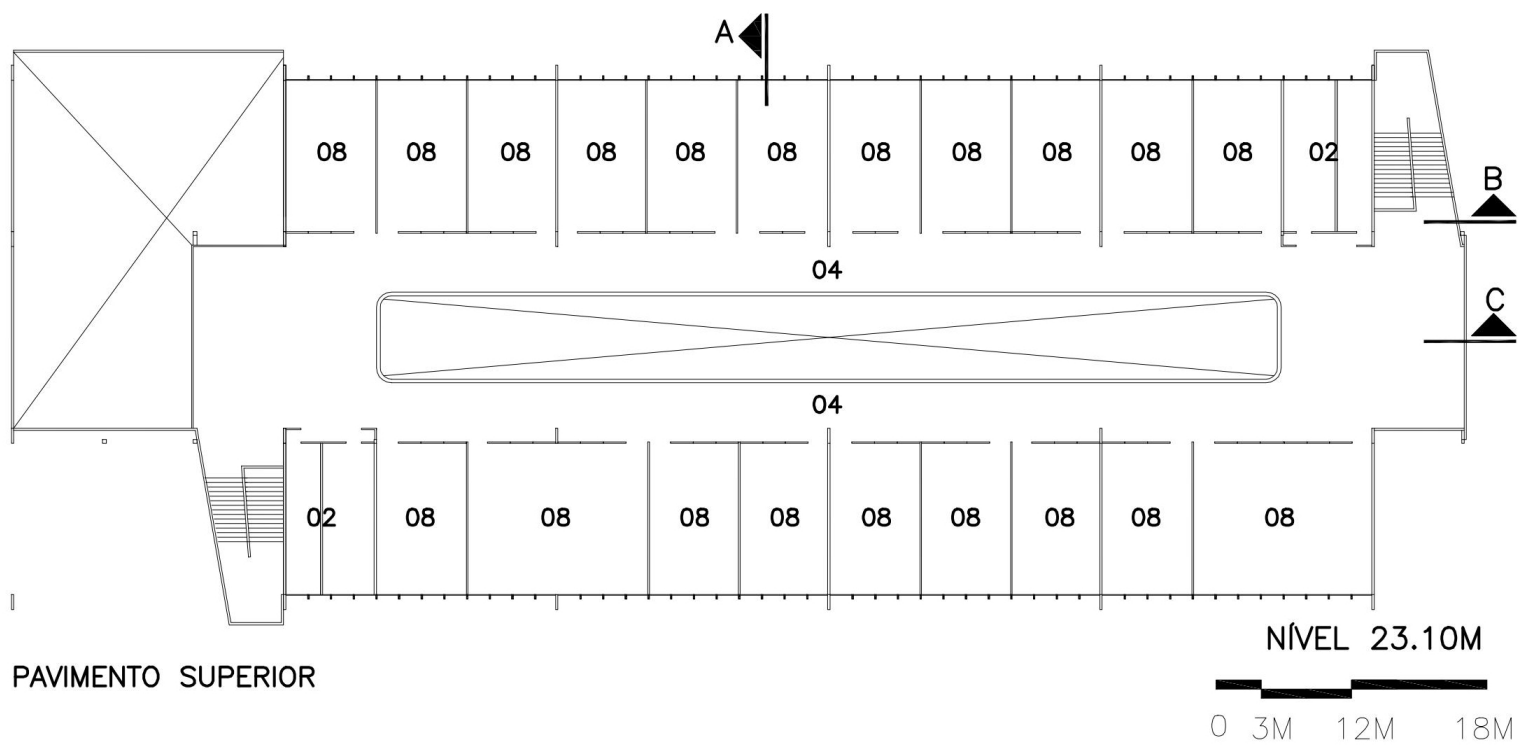

Figura 4

Módulo $1^{\circ}$ Etapa de Construção do bloco didático Plano UMA: Mapa Base - Prancha 15 do Plano de Implantação Imediata - $1^{\circ}$ Sub-Etapa Plano UMA .

Fonte: Arquivo digital disponível no COMCAP-UEM. Redesenho do autor Renan Avanci.

Legenda:

01 - Laboratório, 02 Sanitário, 03 - Equipamento, 04 - Circulação, 05 - Departamento, 06 - Biblioteca, 07 - Pátio coberto, 08 - Sala, 09 - Acesso principal. 


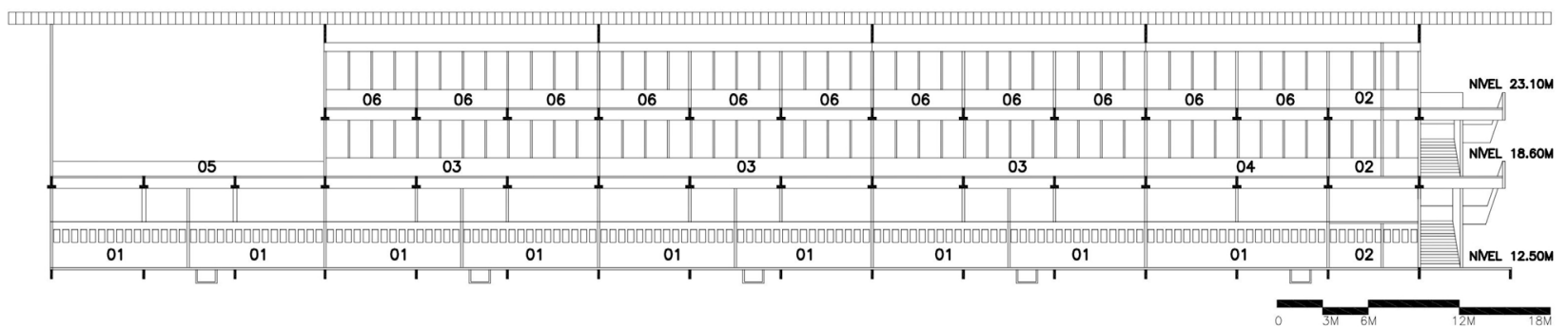

Figura 5

Módulo $1^{\circ}$ Etapa de Construção do bloco didático Plano UMA: Mapa Base - Prancha 15 do Plano de Implantação Imediata - $1^{\circ}$ Sub-Etapa Plano UMA .

Fonte: Arquivo digital disponível no COMCAP-UEM. Redesenho do autor Renan Avanci.

Legenda:

01 - Laboratório, 02 - Sanitário, 03 - Departamento, 04 - Biblioteca, 05 - Pátio Coberto, 06 - Salas de Aulas.

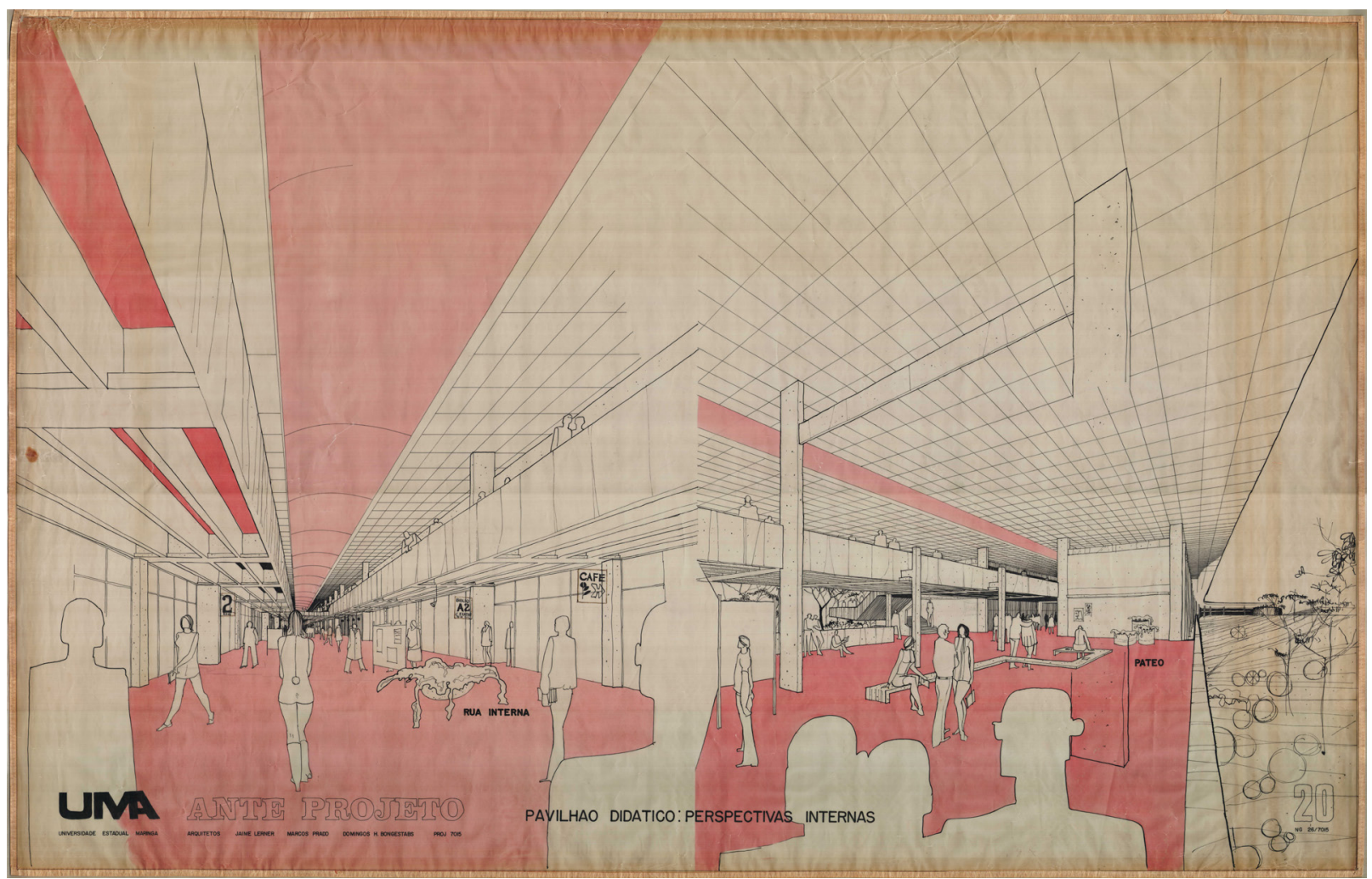

Figura 6

Corredor central do bloco did[ático - Plano UMA: Mapa Base - Prancha 19 do Plano de Implantação Imediata - $1^{\circ}$ Sub-Etapa Plano UMA .

Fonte: Arquivo digital disponível no COMCAP-UEM.

O destaque para a circulação de pedestre é outro ponto de aproximação com as megaestruturas universitárias lineares, pois a ideia de reunir um grupo de atividades em um alongado edifício, de fato, designou um eixo dominante de acesso e percurso do transeunte. No plano de Lerner, esta questão foi representada por uma via longitudinal classificada como uma grande "rua de pedestres" e localizada no pavimento intermediário da edificação. Este eixo, a partir do acesso pela Grande Praça, direcionaria os usuários para os outros dois pavimentos do edifício. 
Em relação aos aspectos construtivos, os sistemas lineares optam pela modulação estrutural. Uma postura que facilitaria a viabilização de um edifício a ser construído, em muitos casos, por etapas. A equipe Lerner modulou o bloco didático do Plano UMA em módulos de 18 metros e sub-módulos de $12,6,3$ e 1.5 metros. Esse sistema contribuiria tanto para a viabilização das três etapas previstas para a implantação do bloco, quanto para a flexibilização dos arranjos espaciais internos que poderiam se ajustar de acordo com sub-módulos especificados.

Como forma de atender a dinâmica do ensino superior, a flexibilização do espaço interno das estruturas lineares é essencial. Em todo o projeto da UnB, por exemplo, essa questão esteve presente. "Os arquitetos entendiam que o desafio era a própria dinâmica com que a ciência contemporânea se apresentava e uma boa solução técnica seria fundamental para responder a essa nova realidade" (MÓDULO,1963 apud ALBERTO, 2008, p. 275-276). O próprio setor de laboratórios do ICC foi pensado com vários recursos de flexibilidade. Apesar da largura fixa, o comprimento dos ambientes poderia variar de acordo com o setor de pesquisa instalado, do mesmo modo, os laboratórios poderiam crescer utilizando-se do piso superior ou da área livre gerada entre os dois volumes paralelos da edificação.

A estrutura do pavilhão linear do Plano UMA, embora não tenha representado seus pontos de flexibilidade do mesmo modo que Niemeyer esquematizou para UnB, também poderia arranjar e adequar às atividades didáticas a partir do sistema modular. A largura das salas permaneceria fixa, contudo, existindo a possibilidade do seu crescimento longitudinal.

Na verdade, a concepção do edifício em linha padronizado e modulado, apesar das diversas possibilidades de arranjo e rearranjos espaciais internos, não se pode negar que apresenta rigidez externa. Qualquer expansão lateral não se concretiza sem alterar a forma do edifício que se constrói a partir de um eixo longitudinal dominante. Esta condição espacial foi um dos principais aspectos de revisão do Grupo de Planejamento Físico (GPF) a respeito da efetiva concretização do Plano UMA. A expansão do pavilhão didático ficaria limitada em sua dimensão longitudinal acarretando em algum momento não conformidade física com as evoluções acadêmicas. Portanto, a análise da própria Universidade sobre o primeiro plano da equipe Lerner considerou que o partido adotado não permitiria crescimento transversal do edifício, a menos que se prejudicasse a forma (UEM, 1976). 
Assim, de um lado a organização espacial do setor didático do Plano UMA em torno da proposta de um bloco único propôs um espaço integrador das atividades de ensino. A reunião de educadores e universitários de todas as áreas de graduação em um único espaço encurtaria distâncias e conectaria o aprendizado com a pesquisa. Por outro lado, questionou-se às possibilidades de expansão e viabilização da grande estrutura linear. Apesar da modulação estrutural e da flexibilidade interna, a Universidade deveria cumprir todas as etapas construtivas para assim afirmarem o edifício didático como um equipamento educacional integrador do espaço universitário.

\section{A representação em malha: o plano de 1977}

Ao tratarmos das intenções da UEM em elaborar um novo plano arquitetônico e urbanístico para o campus - sete anos depois da aprovação do primeiro projeto podemos constatar uma negação do partido linear configurado pelo Plano UMA para o seu setor didático. Nesta nova proposta notamos duas premissas fundamentais consideradas pela Comissão de Planejamento da Universidade (CPU) para a edificação do novo campus.

A primeira premissa foi de ordem econômica devido à consciência da administração da instituição sobre a permanente escassez de recursos financeiros. Neste sentido, as construções no campus não deveriam ser suntuosas, o que de imediato negava as grandes estruturas lineares propostas pelo primeiro plano, mesmo que elas fossem concebidas por etapas.

Outro ponto preliminar a ser atendido pelos arquitetos na elaboração da nova proposta referiu-se ao partido geral do campus. A Comissão propôs que a configuração espacial do segundo projeto deveria ter uma circulação de pedestres com áreas de encontro a céu aberto e as edificações didáticas deveriam ramificarse a partir desta circulação. Este sistema também deveria permitir a adição de novos blocos sem interferir no funcionamento das edificações já existentes (UEM, 1976). De fato, estas diretrizes também negavam a espacialização do Plano UMA que propunha um sistema de circulação sistematizado sob o edifício único.

Neste contexto, a estratégia espacial da malha proposta pela equipe Lerner como concepção exclusiva do setor didático no segundo projeto para a UEM atenderia precisamente as premissas fundamentais almejadas pela comissão de planejamento da Universidade. 
3 o plano inicial apresentou uma modulação de $90 \mathrm{~m} \times 15 \mathrm{~m}$, contudo a partir da análise do esboço do projeto pelo Grupo de Trabalho de planejamento Físico (GTPF) da UEM optou-se por uma diminuição dos módulos para $60 \mathrm{~m} \times 15 \mathrm{~m}$ a fim de diminuir os percursos.
De acordo com o Memorial do projeto, a malha de fato tinha como principal objetivo organizar as funções didáticas sobre o terreno universitário estabelecendo um sistema organizacional para a Universidade.

\begin{abstract}
A malha é, portanto o suporte do desenvolvimento das instalações didáticas da UEM e a geratriz da composição do campus e foi dimensionada de forma a adequar as dimensões necessárias às edificações, possibilitar flexibilidade de arranjos e adequar os percursos à escala de tempos convenientes ao deslocamento a pé em face das informações dos fluxos intersetoriais (LERNER et al, 1977, s.p).
\end{abstract}

Em específico, a malha regular como o artefato de organização espacial do campus foi constituída por três eixos oblíquos iguais de $60 \mathrm{~m} \times 15 \mathrm{~m}^{3}$ que quando interseccionados formavam espaços hexagonais e triangulares entre os blocos. Os espaços triangulares conformaram-se como pátios e os hexagonais edificaram núcleos de instalação dos equipamentos de apoio como auditório, cantina e instalação sanitária.

De acordo com as definições do plano, os pátios formados pelas edificações na malha não se conformariam como ambientes estanques, mas como partes integrantes do conjunto. "Partes de um circuito paisagístico integrado de cheios e vazios" (LERNER, et al, 1977 , s.p). Do mesmo modo, os núcleos hexagonais em cada ponto de encontro de intersecção das edificações na malha deveria, pelas suas próprias propriedades estruturais, estabelecer uma unidade paisagística para o conjunto.

Como princípios formais, a concepção da malha adotou uma diferenciação dos blocos didáticos da dos núcleos hexagonais de apoio. Esta opção possibilitaria uma independência construtiva entre os dois elementos, além de serem instalações díspares que organizaria visualmente todo o conjunto (LERNER et al, 1977).

Outro princípio referiu-se à verticalização das edificações, principalmente das didáticas. O plano estabeleceu blocos de ensino de até três pavimentos, contudo não restringiu os edifícios que deveriam ser verticalizados, apesar de indicarem no plano uma proposta de verticalização. Caberia à Universidade dinamizar esta questão de acordo com suas necessidades físicas. De todo o modo, a equipe de arquitetos afirmou que a opção de edificações com apenas um pavimento seria suficiente para garantir a integridade formal do sistema, possibilitando, segundo eles, uma maior riqueza plástica da arquitetura face à declividade do terreno. Por outro lado, caso fosse necessário o crescimento em altura dos edifícios, os mesmos deveriam acom- 
panhar a unidade proposta pela malha arquitetônica (LERNER et al, 1977).

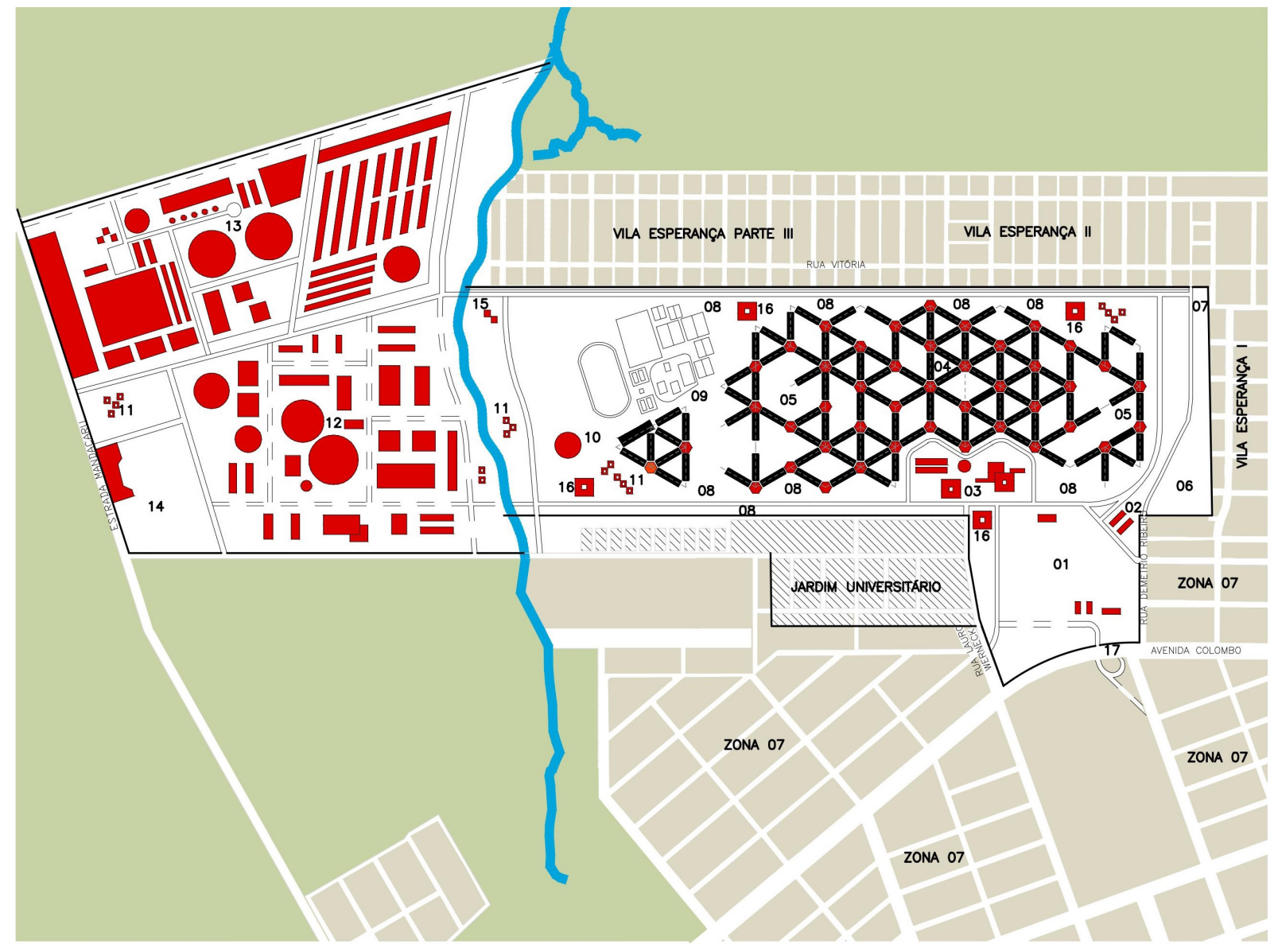

Figura 7

Implantação Geral 2 Plano.Fonte: Mapa Base - Pranchas 01 - Plano Piloto 1977.

Fonte: Disponível na DOP/PTO Redesenho do autor Renan Avanci.

Legenda:

01 - Praça de acesso / Prestação de serviços, 02 - Manutenção, 03 - Biblioteca / Restaurante / Auditório / Reitoria / Capela , 04 - Blocos Didáticos, 05 - Pesquisa, 06 -Habitação, 07 - Caixa d'água / Estação meteorológica, 08 - Estacionamentos, 09 - Centro Esportivo, 10 - Anfiteatro / Concha acústica, 11 - Amenização / Lazer, 12 Laboratórios pesados, 13 - Estações experimentais / viveiro, 14 - Hospital Regional, 15 - Estação de Tratamento e Esgoto, 16 - Restaurantes universitários, 17 - Passagem subterrânea

Como visto, as instalações de ensino foram posicionadas em conformidade com o desenho triangular da malha planejada para o setor didático. O posicionamento dessas instalações conformaria o que chamamos nessa pesquisa como "matriz didática". A caracterização dessa matriz dar-se-ia por meio de seis blocos lineares interligados por núcleos de instalações de apoio no formato hexagonal. Em cada face desse núcleo implantar-se-ia um pavilhão didático. Ao centro da matriz, a disposição de mais um núcleo de apoio também no formato hexagonal interligaria três blocos de ensino conformando entre eles pátios e áreas livres. Em síntese, a matriz apresentou um desenho muito próximo à configuração hexagonal dos alvéolos de uma colmeia. 


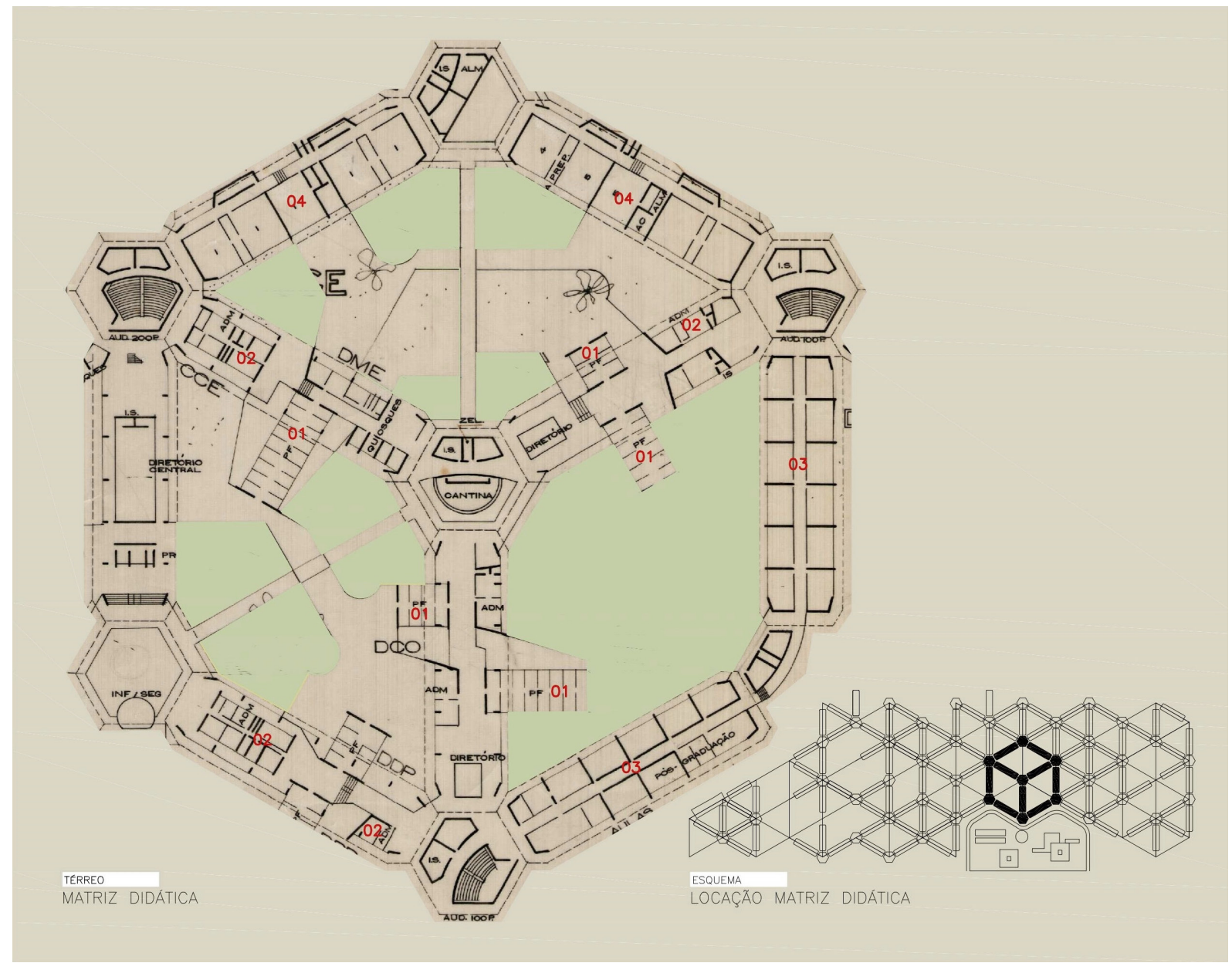

Figura 8

Matriz Didática Pavimento térreo.

Fonte: Mapa Base - Pranchas 08 - Plano Piloto 1977. Disponível na DOP/PTO.

Neste sentido, a conformação da malha e consequentemente das matrizes de seu desenvolvimento dar-se-ia por meio de dois tipos de edificações. Os edifícios didáticos e os núcleos hexagonais de instalações de apoio.

Os edifícios didáticos teriam dimensões iniciais de $15 \mathrm{~m}$ x 60m, planta livre e configuração interna por meio de divisórias pré-fabricadas do tipo leve ou de concreto celular. As edificações didáticas foram planejadas de forma a obter a maior flexibilidade espacial possível, racionalidade construtiva, baixo custo e rapidez nas etapas de construção (LERNER, et al, 1977).

De modo geral, as instalações de ensino foram pensadas apenas com um único pavimento. De acordo com os arquitetos, essa postura já atenderia de forma adequada a demanda da Universidade (LERNER, et al, 1977). Apesar disso, também propuseram algumas edificações com até três pavimentos. Este posicionamento projetual, por parte da equipe Lerner demons- 
trou uma possibilidade de crescimento vertical da instituição universitária e não totalmente uma regra a ser seguida por toda a malha.

Portanto, a Universidade cresceria em altura de acordo com a dinâmica do seu desenvolvimento cabendo à instituição acadêmica estipular qual bloco deveria ser verticalizado. Apresentamos essas considerações como forma de mostrar que as matrizes de crescimento poderiam variar em suas alturas, no entanto, permaneceria sempre o formato hexagonal proposto pela malha.

De fato, o edifício didático base para o ensino e a pesquisa proposto pelo segundo plano possuiu apenas um pavimento. Utilizou-se o sistema construtivo convencional com tijolos aparentes e cobertura metálica. Internamente, o bloco configurou-se por meio de um corredor central distribuindo as salas de aula e os laboratórios em duas alas laterais Os acessos ao edifício dar-se-iam pelas suas extremidades longitudinais. Quanto às edificações com mais pavimentos, os arquitetos propuseram o mesmo sistema construtivo e a mesma disposição interna das salas de aula e dos espaços para pesquisa proposto na configuração do edifício base. Contudo mantinha-se com um pavimento térreo configurado para abrigar também as salas de apoio aos universitários e departamentos, como administração, sala dos professores, salas de reuniões.

Os outros dois sistemas de crescimento do setor didático foram chamados de expansão modular e de expansão por derivação. Pela expansão modular, agregar-se-ia internamente à matriz didática novos pavilhões de acordo com a necessidade da instituição universitária. Pela expansão por derivação criar-se-ia sobre a modulação básica da matriz um sub-módulo conectando dois pavilhões didáticos por blocos intermediários implantados no pátio entre os mesmos. De acordo com os autores do plano, a implantação do bloco entre os pavilhões visava atender as necessidades de multiplicação de laboratórios que poderiam funcionar em proximidade com os laboratórios já existentes. Segundo eles, era uma proposta econômica, pois permitiria reduzir consideráveis recursos com as expansões modulares. Esse último sistema, embora permitisse um acréscimo de $50 \%$ da área de um pavilhão didático, deveria ser utilizado de forma comedida na conformação da malha uma vez que poderia aumentar o número de edificações e congestionar os espaços livres entre elas (LERNER, et al, 1977). 


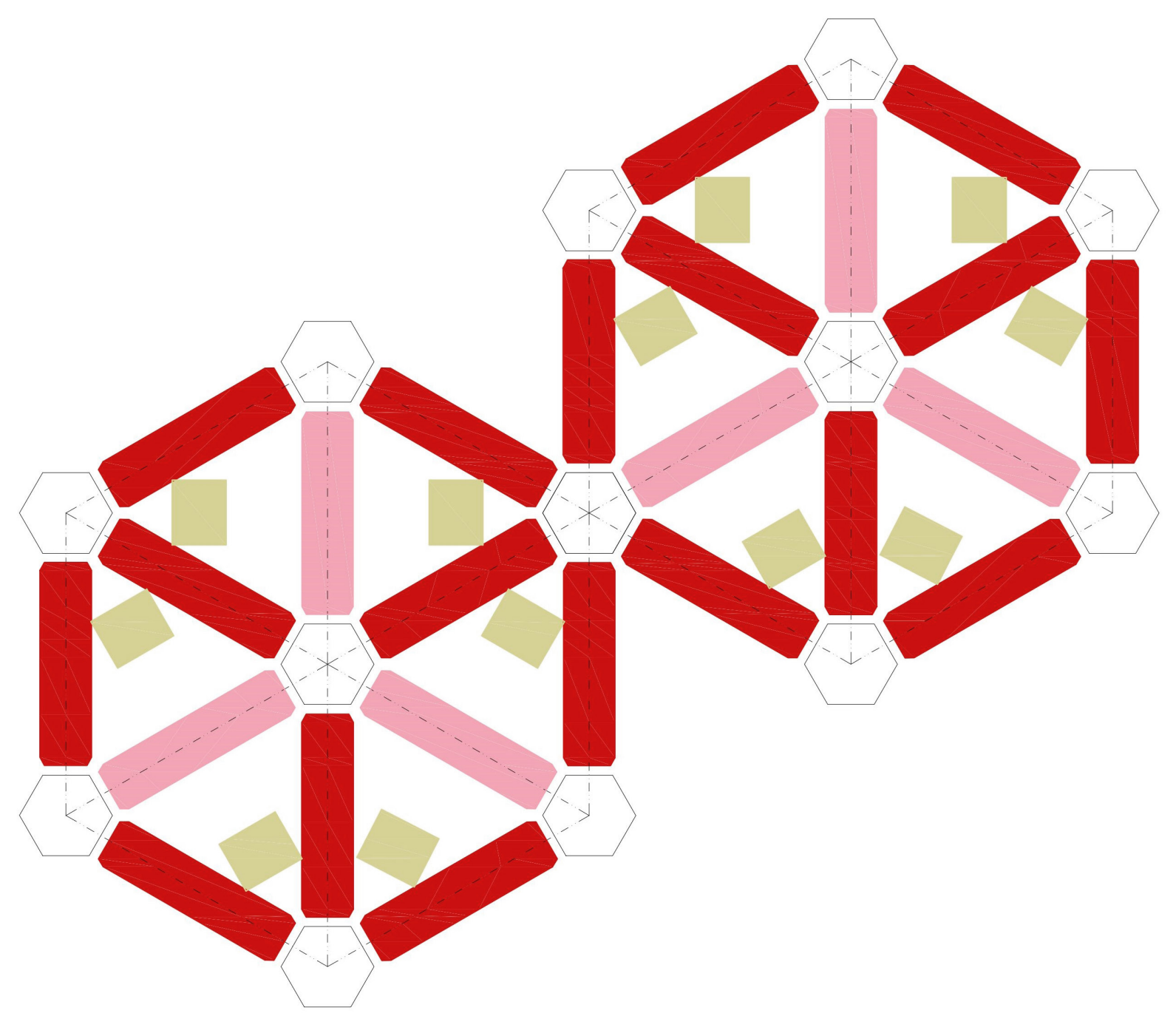

Figura 9

Esquema de Crescimento Modular dos Blocos Didáticos - Plano Piloto 1977.

Fonte: Esquema base (LERNER, et al, 1977). Redesenho do autor Renan Avanci. Legenda:

Malha Projetada

Malha em Expansão Modular

Malha em Expansão por Derivação

Núcleos de apoio. Auditório / Sanitário / Cantina

Por meio das matrizes didáticas estabeleceu-se um sistema de referência nomeando os blocos de ensino e os blocos de laboratórios como forma de facilitar a orientação do usuário dentro do setor didático.

Neste sentido, foi proposta uma segunda malha sendo basicamente como uma trama virtual quadriculada implantada sobre a malha triangular de fixação dos blocos educacionais. A cada setenta e cinco metros, onze eixos nomeados em ordem alfabética $(A, B, C$, 
$D, E, F, G, H, I, J, K)$ fracionavam virtualmente o campus em seu sentido longitudinal. Do mesmo modo, a cada quarenta e cinco metros de distância, dez eixos numerados de 1 a 10 segmentavam transversalmente o espaço acadêmico no sentido norte - sul. O critério de nomeação dos blocos dar-se-ia, então, pelo posicionamento do edifício didático em conformidade com a malha virtual. Uma vez o edifício sendo implantado entre o eixo longitudinal $\mathrm{C}$ e os eixos transversais 6 e 7, por exemplo, seria nomeado como Bloco C67.

Este critério de referência seguia-se por todos os pavilhões didáticos conforme sua disposição nos eixos virtuais.

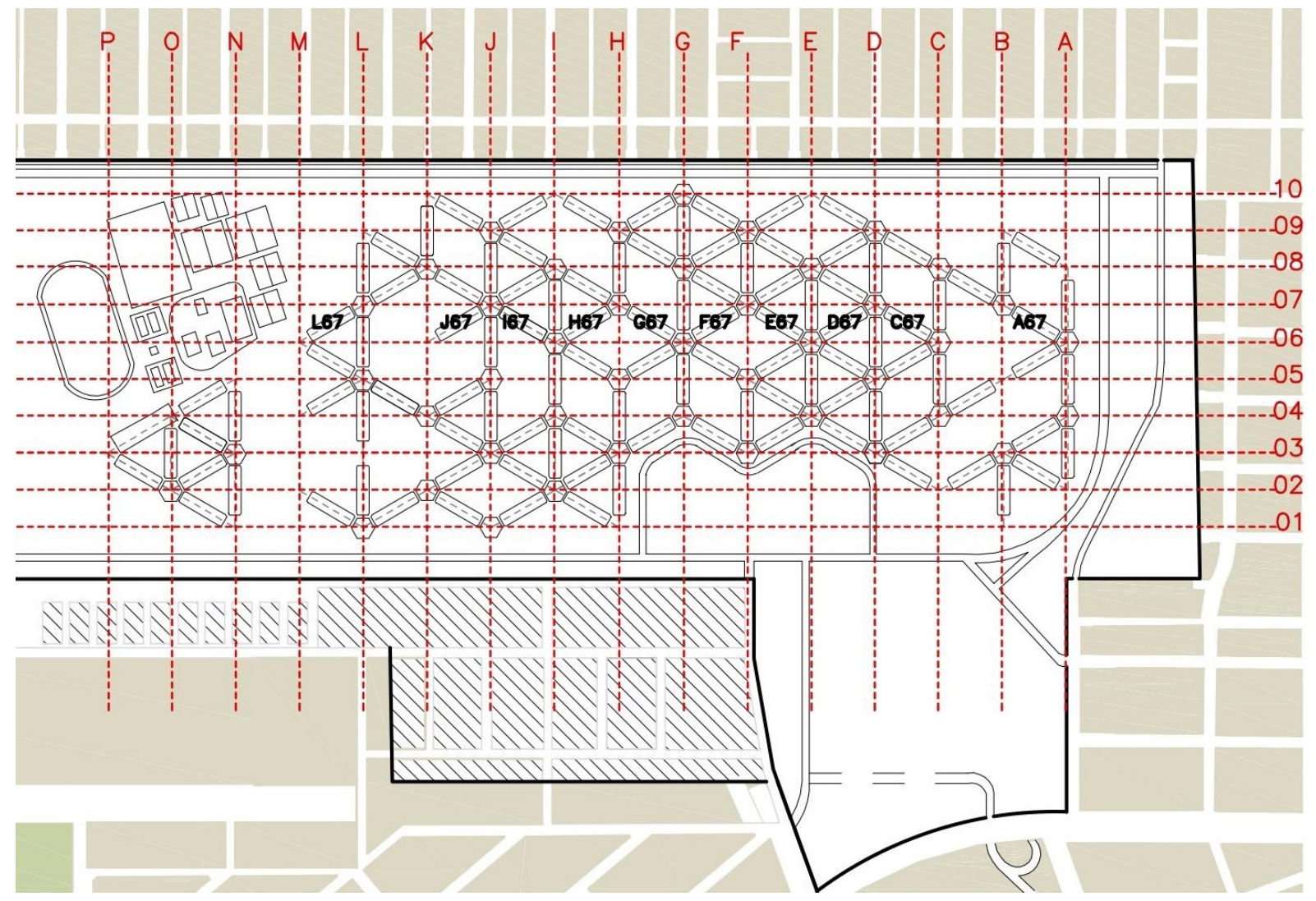

Figura 10

Malha virtual de nomeação dos blocos didáticos.

Fonte: Mapa Base Plano Piloto 1977. Disponível na DOP/PTO. Elaboração do autor Renan Avanci.

De acordo com a análise deste segundo plano pela Comissão de Planejamento da Universidade, apesar da estrutura espacial atender os objetivos almejados pela instituição, a disposição dos blocos criou uma sensação de enclausuramento, impedindo o observador do domínio visual da paisagem universitária e à apropriação do seu território como um todo (UEM, 1976). Na verdade, aos olhos da Comissão, a malha triangular configurou um percurso confuso entre as edificações. Uma trajetória em linhas quebradas sem permitir uma 
orientação clara para o usuário necessitando, assim, de uma programação visual complexa de identificação dos blocos didáticos.

\section{Considerações}

As díspares formas de configuração do setor didático de ambos os planos apresentados tratou de responder, como pudemos notar, tanto às estratégias espaciais de implantação das edificações em um campus universitário, quanto aos princípios estéticos de organização de uma instituição acadêmica. São representações que, apesar das distâncias formais, traduzem uma preocupação com a unidade do território, com a integração das atividades e com a flexibilização e compactação dos espaços de ensino.

Em contrapartida, a transição entre essas representações como propostas arquitetônicas foi marcada por conceitos que direcionaram a alternância de uma configuração simples e legível para uma implantação complexa e labiríntica. De uma identidade funcional e plástica proposta pela concepção arrojada do pavilhão linear do primeiro plano, considerando sua negação devido a sua rigidez externa, para a malha triangular concebida pelo segundo plano, com implicações que conduzem ao enclausuramento e a ilegibilidade do espaço universitário.

\section{Referências}

ALBERTO, K. C. Formalizando o ensino superior no Brasil na década de 1960: a cidade universitária da Unb e seu projeto urbanístico. Rio de Janeiro: UFRJ, Tese de Doutorado, Departamento de Urbanismo da UFRJ, 2008.

ALBERTO, K. C. Interfaces Brutalistas: Megaestruturas universitárias. Curitiba: Anais do $10^{\circ}$ Seminário Docomomo Brasil, 2013.

AVANCI, R. A. UEM, campus e planos: formalizando a universidade planejada. Maringá: UEM, Dissertação de mestrado, Departamento de arquitetura e urbanismo da UEM, 2016.

BANHAM, R. Megaestructuras: futuro urbano del passado reciente. Barcelona: Gustavo Gili, 1976.

CABRAL, C. P. C. Grupo Archigram, 1961 -1974: uma fábula da técnica. Barcelona: ET$\mathrm{SAB}$, Tese de doutorado, Universidade Politécnica da Catalunha, 2002.

CABRAL, C. P. C. Uma fábula da técnica na cultura do Estado do bem estar: grupo Archigram, 1961-1974. Cadernos de Arquitetura e Urbanismo, v.11, n.12, p. 247-263, 2004.

COMCAP-UEM - Complexo de Centrais de Apoio à Pesquisa. 
CORDOVIL, F.C.S. A aventura planejada: engenharia e urbanismo na construção de Maringá, $P R, 1947$ a 1982. São Carlos, Tese de doutorado, Universidade de São Paulo, Instituto de Arquitetura e Urbanismo de São Carlos, 2010.

DOP/PTO-UEM - Diretoria de obras e projetos - Divisão de projeto.

LERNER, J.; BONGESTABS, D.; PRADO, M. Memorial justificativo Plano Piloto. UEM, 1977.

MAHLER, C. R. Territórios Universitários: tempos, espaços, formas. Brasília: UnB, Tese de Doutorado em Arquitetura e Urbanismo, 2015.

MARINGÁ. Relatório Maio 1971 - UMA Universidade de Maringá. Maringá, 1971.

MONTANER, J. M. Depois do movimento moderno: arquitetura da segunda metade do século XX. Barcelona: Gustavo Gili, 2001.

MONTANER, J. M. Sistemas arquitetônicos contemporâneos. Barcelona: Gustavo Gili, 2009.

UEM. Plano Piloto do Câmpus Universitário - Plano Diretor - Anteprojeto e projetos definitivos do Câmpus. Maringá. Maringá: UEM, 1976. 